\title{
Pseudothrombocytopenia in Obstetric Patients: Case Reports
}

\section{- Betül YAKIŞTIRANa, - DOrhan ALTINBOĞAa, (1)Turhan ÇAĞLAR}

aDepartment of Obstetrics and Gynecology, Ankara Zekai Tahir Burak Women's Health Training and Research Hospital, Ankara, TURKEY

Received: 06 Oct 2019

Received in revised form: 03 Nov 2019

Accepted: 21 Nov 2019

Available online: 29 Nov 2019

\section{Correspondence:}

Betül YAKIŞTIRAN

Ankara Zekai Tahir Burak Women's Health Training and Research Hospital, Department of Obstetrics and Gynecology, Ankara, TURKEY

btlengin@gmail.com
Copyright $(02019$ by Türkiye Klinikleri

\begin{abstract}
Thrombocytopenia is defined as platelet count of less than $150 \times 10^{\wedge} 3 /$ uL. During pregnancy, haemodilution and increased aggregation lead to physiological thrombocytopenia and it has no harmful effects on pregnancy. Pseudothrombocytopenia is defined as in vitro platelet clumping that results falsely low platelet counting by automated cell counters. Before diagnosis, we should exclude probable severe pregnancy-induced diseases leading to thrombocytopenia during pregnancy such as preeclampsia, gestational thrombocytopenia. It is important to avoid unnecessary intervention and treatment. Herein, we report three cases with profound artifactual thrombocytopenia during pregnancy.
\end{abstract}

Keywords: Pregnancy; pseudothyrombocytopenia; etylendiaminetetracetic ascit

hrombocytopenia is defined as platelet count of less than $150 \times 10^{\wedge} 3 / \mathrm{uL} .{ }^{1}$ During pregnancy, haemodilution and increased aggregation lead to physiological thrombocytopenia and it has no harmful effects on pregnancy. In general, the leading cause of thrombocytopenia is diagnosed as gestational thrombocytopenia and similarly, it has no adverse maternal-fetal effects. Occasionally, thrombocytopenia can be a life threatening condition in pregnancy when is due to pregnancy-related hypertension spectrum (preeclampsia, eclampsia), HELLP syndrome, acute fatty liver of pregnancy, immune thrombocytopenic purpura (ITP), hemolytic uremic syndrome (HUS), thrombotic thrombocytopenic purpura (TTP), sepsis, malignancy or disseminated intravascular coagulapathy (DIC). ${ }^{1,2}$ Pseudothrombocytopenia is another reason of iatrogenic thrombocytopenia. ${ }^{3,4}$

Pseudothrombocytopenia is defined as in vitro platelet clumping that results falsely low platelet counting by automated cell counters. The main reasons of pseudothrombocytopenia can be classified as a. Cumulation of thrombocytes due to Etylendiaminetetracetic ascit (EDTA) in blood hemogram tubes b. Platelet satellitism c. Giant platelets. EDTA, sodium citrate and heparine which are in blood specimen tubes and inhibit clotting blood samples by chelating calcium, are associated with pseudothrombocytopenia. ${ }^{5}$ Before diagnosis, we should exclude probable severe pregnancy-induced diseases leading to thrombocytopenia during pregnancy. It is important to avoid unnecessary intervention and treatment. 
Herein, we report three cases with profound artifactual thrombocytopenia during pregnancy.

\section{CASE REPORTS}

\section{CASE 1}

A 25-year-old woman with gravida 3 parity 2 was admitted to emergency obstetric clinic with complaints of uterine contraction and back pain. On clinical examination, body temperature $\left(36.8^{\circ} \mathrm{C}\right)$, blood pressure $(100 / 70 \mathrm{mmHg})$, hearth rate $(92$ pulse/min), oxygen saturation (98\%) were normal. On pelvic examination, she had 7 centimeter of cervical dilatation and $\% 80$ cervical effacement. Ultrasound scan showed cephalic presentation, normal amniotic volume (single deepest vertical pocket: 36 milimeter) and anterior placenta. The estimated fetal weight was calculated as $2400 \mathrm{~g}$; below 10 percentile. After her examination, blood samples were sent to the laboratory and the laboratory tests including biochemical [aspartate aminotransferase (AST), alanine aminotransferase (ALT) creatinine, uric aside, lactate dehydrogenase $(\mathrm{LDH})$ ] and coagulation parameters [activated partial thromboplastin time (aPTT), international normalized ratio (INR), prothrombin time (PT)] were within normal ranges except complete blood count (CBC). Laboratory findings demonstrated platelet counts of $5 \times 10^{\wedge} 3 / \mathrm{uL}$ and repeated CBC demonstrated similar platelet counts, a peripheral blood smear was sent to hematology department. It was seen that platelet clustering making it pseudothrombocytopenia and estimatedly platelet count was $100 \times 10^{\wedge} 3 / \mathrm{uL}$ (Figure 1, Figure 2). Pe- ripheric smear was prepared from EDTA-contained blood tube. It was considered pseudothrombocytopenia and there was no transfusion indication. She had an uneventful normal vaginal delivery of a female infant. The newborn was healthy $(2500 \mathrm{~g}$, APGAR score 9, length $50 \mathrm{~cm}$ and head circumference $35 \mathrm{~cm}$ ). On the first day after delivery, the complete blood count of the neonate revealed normal platelet count (269x10^3/uL). Her physical examination was completely normal. After delivery, the patient remained well and her postnatal sixth hour CBC control revealed pseudothrombocytopenia and hemoglobin level was $11.5 \mathrm{~g} / \mathrm{dL}$. On follow-up sonographic examination, there was no pathologic image suggesting haemorrhage. She was discharged from the hospital the next day. Informed consent form was obtained from the patient.

\section{CASE 2}

A 24-year-old woman with gravida 4, parity 2, abortus 1; and with no co-morbidities was admitted to emergency obstetric unit with complaints of uterine contraction and amnion fluid leakage. On her pelvic examination, she had $10 \mathrm{~cm}$ of cervical dilatation and $100 \%$ effacement. Her vital signs were completely normal (blood pressure 120/76 $\mathrm{mmHg}$, hearth rate $86 \mathrm{pulse} / \mathrm{min}$, body temperature $36.4{ }^{\circ} \mathrm{C}$, oxygen saturation $98 \%$ ). On ultrasonographic examination, there was no pathologic finding. Her preoperative basic blood samples were sent to the laboratory. Shortly after her admission to the hospital, she delivered a 3410 g, healthy female infant. After delivery, blood sam-

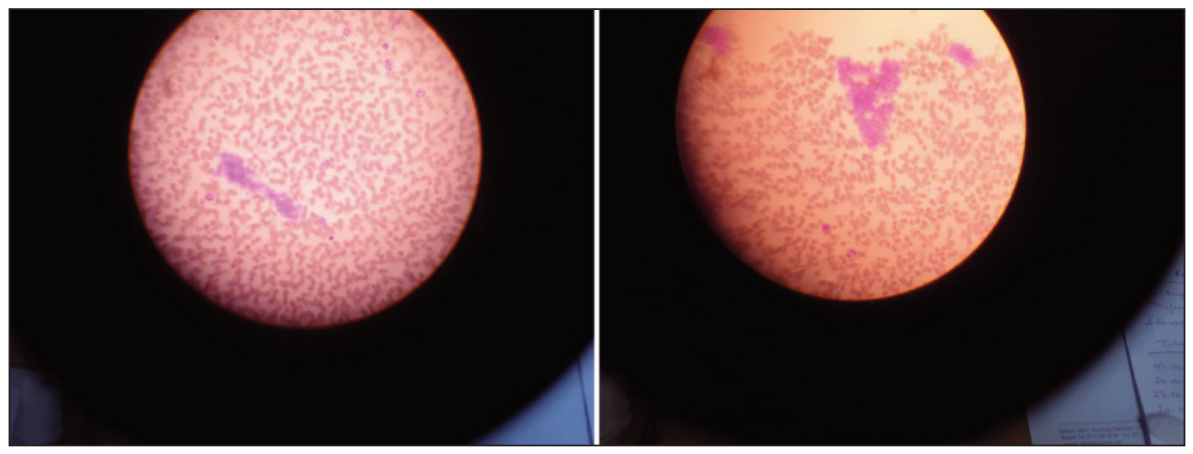

FIGURE 1, 2: Aggregation of platelets in the peripheral blood smear with EDTA. 
ple results revealed normal parameters (AST, ALT, creatinine, uric aside, BUN, CRP, INR, aPTT, PT) except CBC. The platelet value in EDTA- tube was $33 \times 10^{\wedge} 3 /$ uL. Peripheral blood smear was sent to the laboratory and the result was reported as 'clustering thrombocytes, calculated platelet count was estimatedly $75 \mathrm{cx} 10^{\wedge} 3 / \mathrm{uL}$ '. On follow-up examination after delivery, her vital signs were completely normal and she had no more bleeding tendency than expected. Control CBC revealed a normal hemoglobin level of $10.8 \mathrm{~g} / \mathrm{dL}$. The newborn's blood samples was investigated and no pathologic findings were observed regarding thrombocytopenia. After two days she was discharged from the hospital. Informed consent form was obtained from the patient.

\section{CASE 3}

A 29-year-old woman with Type 2 diabetes mellitus, chronic hypertension, morbid obesity and new-onset thrombocytopenia was referred to our hospital at $34^{\text {th }}$ gestational week. She was hospitalized to regulate blood sugar level and to ascertain the etiology of thrombocytopenia. She was receiving alpha methyldopa tid and insulin treatment. Ultrasound scan showed that fetal growth was beyond than due to gestational age and dating to first trimester crown rump length (CRL) measurement. Her blood pressure was $160 / 90 \mathrm{mmHg}$, fasting blood glucose was $152 \mathrm{mg} / \mathrm{dL}$ on admission to the hospital. Routine blood samples (CBC, biochemistry, urine analysis, coagulation tests) were sent to the laboratory and revealed normal parameters apart from $\mathrm{CBC}$ and spot urine protein. The platelet value in EDTA-tube was $34 \times 10^{\wedge} 3 /$ uL. A 24 -hour urine was collected and the mean measured 24hour urinary protein was $1.5 \mathrm{~g}$. She had no complaints of headache, epigastric pain, diplopia. Control blood samples were sent after 6 hours; AST-ALT levels were below $35 \mathrm{U} / \mathrm{L}$, and platelet counts were $35 \times 10^{\wedge} 3 / \mathrm{uL}$ and $32 \times 10^{\wedge} 3 / \mathrm{uL}$, respectively. Peripheral blood smear was sent to the laboratory and result was reported as 'clustering thrombocytes, calculated platelet count was estimatedly $80 \times 10^{\wedge} 3 / \mathrm{uL}$ '. Recurrent late decelerations was observed following minimal uterine contrac- tion on cardiotocography and she underwent cesarean section with fetal distress indication. A healthy boy was born, $2400 \mathrm{~g} / 46 \mathrm{~cm}$ and with a 9 point Apgar score. Postoperative control CBC revealed low platelet count and biochemical parameters were within normal ranges. Preoperative was administered at a loading dose of $4 \mathrm{~g} / \mathrm{h}$ over $30 \mathrm{~min}$ utes and postoperatively followed by an infusion of $1 \mathrm{~g} / \mathrm{h}$. Informed consent form was obtained from the patient.

\section{DISCUSSION}

EDTA-dependent pseudothrombocytopenia is a rare phenomenon, with in vitro platelet clumping that results falsely low platelet counting by automated cell counters. The estimated prevalence is $0.1 \%$ in general population, however this rate rises up to $2 \%$ in critical illnesses [sepsis, cardiac surgery, rubella, human immune-deficiecny virus (HIV) infection, malignancy] and with drug use and in hospitalized patients. ${ }^{6}$ EDTA is a widely used chelator for hematological testing to avoid the presence of coagulum in blood samples. Specific pathophysiological pathway for EDTA-dependent pseudothrombocytopenia have been identified. In the low temperatures, EDTA leads to a structural change of glycoprotein IIb-IIIa complex, and EDTA dependent anti-platelet antibodies access and bind to glycoprotein IIb. ${ }^{7}$ This binding results in platelet clustering and falsely low platelet counting by automated cell counters.

True diagnosis and management of pseudothrombocytopenia has clinical importance to avoid unnecessary intervention for diagnosis and treatment. In literature, platelet transfusion, splenectomy, bone marrow biopsy have been reported. ${ }^{8}$ At this point, major criteria should be known to make a diagnosis, 1. Platelet count $<100 \times 10^{\wedge} 3 / \mathrm{uL}$. 2. No clinical signs of bleeding diathesis 3. Presence of clumps in EDTA samples 4. Time-dependent fall of platelet count. ${ }^{9}$ It is important because there is no platelet transfusion indication for pseudothrombocytopenia.

Additionally, it should be kept in mind when making a differential diagnosis for thrombocytopenia in pregnancy. The main causes of life-threaten- 
ing and pregnancy-related thrombocytopenia are HELLP syndrome and DIC. As in our cases, there is not enough time to reveal the certain etiology of thrombocytopenia in the course of active labor. Shortness of the time and to decide the delivery mode are stressful for specialist. As known, surgical bleeding can occur when platelet counts are less than $50 \times 10^{\wedge} 3 / \mathrm{uL}$ and $30 \times 10^{\wedge} 3 / \mathrm{uL}$ for vaginal delivery. Initially, to determine the etiology of thrombocytopenia, physical examination can help us. If there is no sign or symptoms of bleeding disorders, completely normal physical examination with lower platelet counts, laboratory is asked to confirm platelet counts with citrated tube or peripheral blood smear regarding to pseudothrombocytopenia. Other laboratory parameters can help us to rule out pregnancy-associate hypertension spectrum (preeclampsia, eclampsia), HELLP syndrome and DIC.

The second important point is the possibility of artifactual thrombocytopenia in newborns. In literature, Korterink et al., reported that this entity in a newborn is due to transplacental transmission of immunoglobulins and reverse after one month. ${ }^{10}$ In our cases, we didn't determine neonatal thrombocytopenia. Obstetricians should inform pediatricians about maternal pseudothrombocytopenia before delivery. If transmission is revealed in a newborn, diagnostic peripheral blood smear is obligatory.
In conclusion, the etiological conditions of thrombocytopenia are in a spectrum from lifethreatening, serious illness; to iatrogenic, artifactual laboratory defects in pregnancy. Before any intervention, blood smear should be interpreted for hemolysis, clustering and multidisciplinary management should be performed.

\section{Source of Finance}

During this study, no financial or spiritual support was received neither from any pharmaceutical company that has a direct connection with the research subject, nor from a company that provides or produces medical instruments and materials which may negatively affect the evaluation process of this study.

\section{Conflict of Interest}

No conflicts of interest between the authors and / or family members of the scientific and medical committee members or members of the potential conflicts of interest, counseling, expertise, working conditions, share holding and similar situations in any firm.

\section{Authorship Contributions}

Idea/Concept: Betül Yakıştıran, Orhan Altınboğa; Design: Betül Yakıştıran,Control/Supervision: Turhan Çağlar, Orhan Altınboğa;Data Collection and/or Processing: Betül Yakıştıran; Analysis and/or Interpretation: Betül Yakıştıran, Orhan Altınboğa; Literature Review: Betül Yakıştıran; Writing the Article: Betül Yakıştıran, Orhan Altınboğa;Critical Review: Turhan Çağlar; Materials: Betül Yakıştıran,Turhan Çağlar.

\section{REFERENCES}

1. Boehlen F. Thrombocytopenia during pregnancy. Importance, diagnosis and management. Hamostaseologie. 2006;26(1):72-4. [Crossref] [PubMed]

2. Myers B. Diagnosis and management of maternal thrombocytopenia in pregnancy. $\mathrm{Br} \mathrm{J}$ Haematol. 2012;158(1):3-15. [Crossref] [PubMed]

3. Sousa SM, Sousa TM, Silva CF, Mendes CC. Pseudothyrombocytopenia: a case of platelet satellitism and phagocytosis by neutrophils. Platelets. 2019;13:1-3. [Crossref] [PubMed]

4. Souza L, Amorim L, Pereira A. In-hospital onset of pesudothyrombocytopenia days before surgery. Case Rep Anesthesiol. 2018;2018:4726036. [Crossref] [PubMed]
[PMC]

5. Akıncı S, Hacıbekiroğlu T, Güney T, Silay K, Baştürk A, Bakanay S. Evaluation of pseudothyrombocytopenia causes. Basic Res J Med Clin Sci. 2014;3(4):24-7.

6. Tan GC, Stalling M, Dennis G, Nunez M, Kahwash SB. Pseudothyrombocytopenia due to platelet clumping: a case report and brief review of the literature. Case Rep Haemotol. 2016;2016:3036476. [Crossref] [PubMed] [PMC]

7. Casonato A, Bertomoro A, Pontara E, Dannhauser D, Lazzaro AR, Girolami A. EDTA dependent thrombocytopenia caused by antibodies against the cytoadhesive receptor of platelet gplla-IIla. J Clin Pathol.
1994:47(7):625-30. [Crossref] [PubMed] [PMC]

8. Yamada JE, Souto AFP, Souzo EO, Nunes CA, Dias CP. Pseudothyrombocytopenia in a patient undergoing splenectomy of an accessory spleen. Case report. Rev Bras Anesthesiol. 2008;58(5):1-3

9. Lippi G, Plebani M. EDTA-dependent pseudothyrombocytopenia: further insides and recommendations for prevention of a clinically threatening artifact. Clin Chem Lab Med. 2012;50(8):1281-5. [Crossref] [PubMed]

10. Korterink JJ, Boersma B, Schoorl M, Porceljin $\mathrm{L}$, Bartels PC. Pseudothyrombovytopenia in a neonate due to mother? Eur J Pediatr. 2013;172(7):987-9. [Crossref] [PubMed] 